\title{
ESPAÇO PÚBLICO E ESPAÇO EDIFICADO: UMA ANÁLISE DOS EQUIPAMENTOS SOCIAIS AGREGADOS ÀS PRACCAS DO CENTRO DE FORTALEZA SOB O ENFOQUE DA ACESSIBILIDADE UNIVERSAL
}

\author{
ROCHA, Carlos Bruno Oliveira (1); \\ SANTIAGO, Zilsa Maria Pinto (2); \\ RIBEIRO, Fernanda Lessa (3) \\ (1) Universidade Federal do Ceará, Graduando \\ e-mail:carlosoliveira@arquitetura.ufc.br \\ (2) Universidade Federal do Ceará, Doutora \\ e-mail:zilsa@arquitetura.ufc.br \\ (3) Universidade Federal do Ceará, Pós-Graduanda \\ e-mail:nadal.ribeiro@hotmail.com
}

\begin{abstract}
RESUMO
O presente trabalho trata das condições de acessibilidade e percepção do ambiente público e edificado. Tem como objetivo aprofundar o debate sobre o comprometimento da geração da inclusão numa área com grande pluralidade de transeuntes, em transporte coletivo público, veículo particular, alternativo e a pé. Equipamentos sociais se enquadram como prédios prestadores de serviços de acesso à cultura, lazer e informação que por atenderem uma demanda diversificada de pessoas são indicadores do nível de qualidade dos espaços construídos. Apresenta resultado da pesquisa de acessibilidade tendo como área de estudo os equipamentos sociais vinculados às praças públicas do Centro de Fortaleza.
\end{abstract}

Palavras chave: Acessibilidade; Equipamentos; Praças; Centro da cidade.

\begin{abstract}
The present work deals with the conditions of accessibility and perception of the public and built environment. Aims to deepen the debate about the commitment of the generation of the inclusion in an area with great plurality of passersby, in public collective transport, private vehicle, alternative and on foot. Social equipments are classified as service providers providing access to culture, leisure and information that, because they meet a diverse demand of people, are indicators of the quality level of the built spaces. It presents the results of the accessibility research having as study area the social equipments linked to the public squares of Fortaleza downtown.
\end{abstract}

Keywords: Acessibility; Equipments; Square; Downtown.

\section{INTRODUÇÃO}

Os equipamentos sociais tais como escolas, centros culturais, espaços de esporte e lazer, dentre outros, exercem papel significativo para convivência das pessoas na cidade como 
locais de permanência e passagem, sendo indispensável assegurar seu acesso e uso universal, inclusive por cidadãos com deficiência ou mobilidade reduzida.

Os resultados do Censo Demográfico 2010 apontaram 45.606.048 milhões de pessoas que declararam ter pelo menos uma das deficiências investigadas, correspondendo a $23,9 \%$ da população brasileira. Dessas pessoas, 38.473 .702 se encontravam em áreas urbanas e 7.132.347, em áreas rurais. O que ressalta a importância da promulgação do Decreto Federal 5.296, de 2 de dezembro de 2004, das normas brasileiras relativas à acessibilidade, como a NBR 9.050/2015 e a NBR 16.537/2016, que conduzem para realização de ações públicas e privadas em prol da aplicação de elementos da acessibilidade e do desenho universal. Mesmo com normas e legislação vigentes, a adequação urbana ainda se encontra defasada em relação a demanda, bem como a formação de profissionais. Faz-se necessário pesquisas nesta área para conquista de novos dados e vivências, para assim chegar a soluções arquitetônicas práticas e de qualidade. Nesse sentido, com o estudo aqui apresentado se pretende contribuir na promoção da melhoria da qualidade espacial para democratização da cidade.

O trabalho em questão, que sucede a análise das condições de acessibilidade das praças públicas do Centro de Fortaleza, passa a focar nos edifícios vinculados a esses espaços avaliados inicialmente, os quais prestam diferentes serviços e recebem grande pluralidade de usuários. Este trabalho, portanto, visa aprofundar o debate sobre o comprometimento da cidade na geração da inclusão. Ressalta-se a importância do espaço público como um bem comum e que, mais que qualquer outro ambiente, deve garantir seu uso livre, oferecendo todos os meios para possibilitar seu proveito.

Tendo consciência da alta demanda de usuários nos equipamentos vinculados às praças do Centro de Fortaleza, dentre os quais se destacam o Centro Dragão do Mar de Arte e Cultura, Mercado São Sebastião e Mercado dos Pinhões, a análise desses espaços se deu por meio de relatórios para que se obtivessem resultados qualitativos e quantitativos das condições de mobilidade e percepção do ambiente de cidadãos com mobilidade reduzida.

Baseados nas normas e parâmetros vigentes sobre acessibilidade, apresentamos nesse artigo os resultados obtidos da pesquisa após análise de quatorze equipamentos vinculados às praças do Centro, com os quais foi possível elaborar um mapeamento geral da situação da acessibilidade na área de estudo, no intuito de verificar como prédios prestadores de serviços de acesso à cultura, lazer e informação atendem à demanda diversificada de seus transeuntes.

\section{DEFINIÇÃO DA ÁREA DE ESTUDO}

A escolha do Centro se justifica pela sua importância histórica para a cidade de Fortaleza, pois além de ser a área da cidade com a maior quantidade de praças, vinte e sete ao total, permanece com grande fluxo de mercadorias, informações e pessoas, em transporte coletivo público, veículo particular, alternativo e a pé, sendo destino de viagens e rota até outros bairros. É uma área que precisa de atenção, seja por sua capacidade de geração de renda e negócios, seja por seu potencial em possibilitar a independência do uso de seu rico espaço por pessoas com deficiência e/ou mobilidade reduzida.

Foi elaborado um mapa com a localização das praças existentes no centro da cidade e assinaladas as que agregam alguma edificação em sua área, conforme a Figura 1.

Figura 1: Mapa do Centro e praças públicas diferenciadas entre as que possuem equipamentos vinculados (azuis) e as que não possuem equipamentos vinculados (amarelas). 


\section{eneac \\ 変}

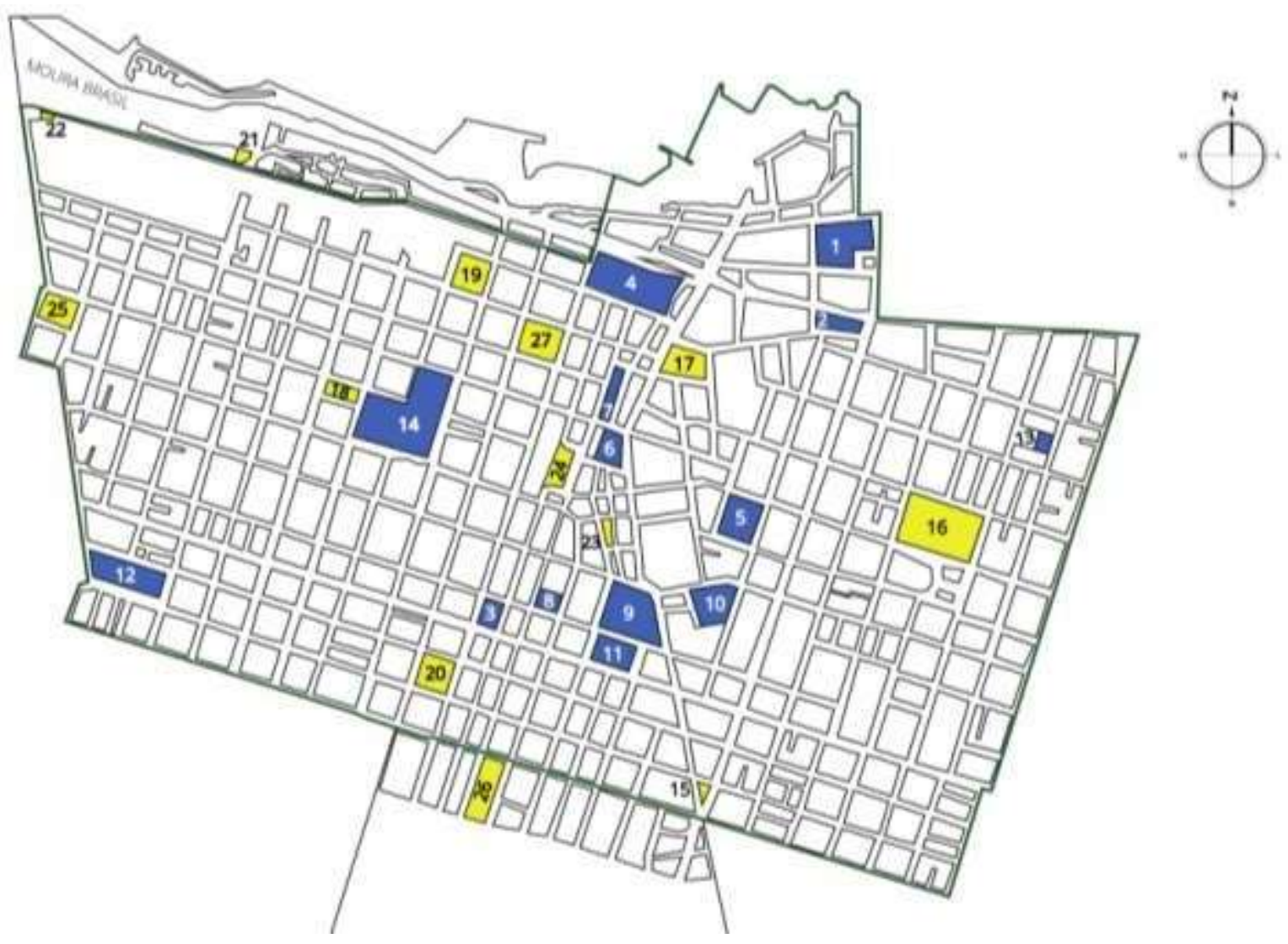

Fonte: Google com adaptação no Adobe Illustrator pela equipe da Pesquisa.

QUADRO 1 - Praças do Centro de Fortaleza e seus equipamentos vinculados.

\begin{tabular}{|c|c|c|}
\hline \multirow{11}{*}{$\begin{array}{l}\text { Praças com } \\
\text { Equipamentos } \\
\text { Vinculados }\end{array}$} & Nome da Praça & Equipamento vinculado \\
\hline & 1 - Almirante Saldanha & Centro Dragão do Mar de Arte e Cultura \\
\hline & 2 - Cristo Redentor & Teatro São José \\
\hline & 3 - Do Carmo & Igreja do Carmo \\
\hline & 4 - Dos Mártires & Passeio Público \\
\hline & 5 - Figueiras de Melo, & Escola Normal \\
\hline & $\begin{array}{l}6 \text { - General Tibúrcio ou } \\
\text { Praça dos Leões }\end{array}$ & Igreja Nossa Senhora do Rosário \\
\hline & $\begin{array}{l}7 \text { - Largo do } \\
\text { Mercado/Largo da } \\
\text { Assembléia/Waldemar } \\
\text { Falcão, }\end{array}$ & $\begin{array}{l}\text { Correios, Largo da Assembléia, Banco do } \\
\text { Brasil }\end{array}$ \\
\hline & 8 - Murilo Borges & Justiça Federal; \\
\hline & 9 - Parque da Liberdade & Parque da Criança; \\
\hline & 10 - Parque Pajeú & Câmara de Dirigentes Logistas (CDL) \\
\hline
\end{tabular}




\begin{tabular}{|l|l|l|}
\hline & 11 - José Júlio & Igreja Sagrado Coração de Jesus \\
\cline { 2 - 3 } & 12 - Paulo Pessoa & Mercado São Sebastião \\
\cline { 2 - 3 } & 13 - Visconde de Pelotas & Mercado dos Pinhões \\
\cline { 2 - 3 } & 14 - José de Alencar & $\begin{array}{l}\text { Instituto do Patrimônio Histórico e Artístico } \\
\text { Nacional - IPHAN }\end{array}$ \\
\hline $\begin{array}{c}\text { Praças sem } \\
\text { Equipamentos }\end{array}$ & $\begin{array}{l}18 \text { - Abraão de Carvalho; } 16 \text { - Bandeira; } 17 \text { - Caio Prado; } \\
\text { Vinculados }\end{array}$ & $\begin{array}{l}21 \text { - Do Muriçoca; 22 - Dos Navegantes; 23 - Dos Voluntários; } \\
24 \text { - Do Ferreira; 25 - Gustavo Barroso; 26 - José Bonifácio; 27 - Vitória. }\end{array}$ \\
\hline
\end{tabular}

Fonte: dados da PMF compilados pela Equipe da Pesquisa

O Centro da cidade apresenta características que justificam o estudo de seus espaços públicos com ênfase nas condições de acessibilidade universal, uma vez que o fluxo de caminhantes é significativo, pois grande quantidade de serviços é prestada nesta área, como também é nó de cruzamento de passagem para vários destinos da cidade. Há ainda, - Programa de adoção de praças pela Prefeitura Municipal de Fortaleza, por meio do qual 130, das 475 praças existentes em Fortaleza, já estão sob parceria de manutenção de pessoas, entidade e empresas, a maioria no Centro, como o Parque da Liberdade, Praça da Sé, Praça Clóvis Beviláqua (da Bandeira), Passeio Público, Praça do Ferreira, Praça Capistrano de Abreu, Praça dos Leões, Praça da Igreja Coração de Jesus, Praça José de Alencar. É uma iniciativa interessante por parte da Prefeitura para diminuir os encargos municipais, mas ao mesmo tempo é importante o acompanhamento da forma como essas adoções estão acontecendo. É necessário saber se nas reformas de manutenção estão sendo implementados parâmetros que garantam as condições de acessibilidade.

\title{
3. METODOLOGIA
}

Após o estudo das recomendações de acessibilidade definidas pelo Decreto 5.296, de 2 de dezembro de 2004 e das normas NBR 9050/2015 e NBR 16537/2016; da diferenciação de praças do Centro que possuem equipamentos vinculados das que não possuem, utilizou-se para pesquisa de campo algumas ferramentas da metodologia de Avaliação Pós-Ocupação (Ornstein, 1992; Rheingantz et al, 2009) considerada

\begin{abstract}
um processo interativo, sistematizado e rigoroso de avaliação de desempenho do ambiente construído, passado algum tempo de sua construção e ocupação. Focaliza os ocupantes e suas necessidades para avaliar a influência e as conseqüências das decisões projetuais no desempenho do ambiente considerado, especialmente aqueles relacionados com a percepção e o uso por parte dos diferentes grupos de atores ou agentes envolvidos (RHEINGANTZ ET AL, 2009, p. 16)
\end{abstract}

$\mathrm{Na}$ pesquisa de campo foi aplicado o procedimento da Avaliação Física dos edifícios selecionados, parte dos procedimentos da Avaliação Pós-Ocupação, constando de análise in loco através de visitas exploratórias do entorno das edificações e da realização de um percurso em todo o edifício, desde seu acesso, para verificar os principais pontos positivos e negativos em relação à acessibilidade física aos ambientes (SANTIAGO, 2005). Estas visitas exploratórias são documentadas com registros fotográficos e anotações das 
características espaciais de cada equipamento por meio de checklist com os parâmetros pré-estabelecidos, com base nos elaborados para a pesquisa da acessibilidade das praças públicas ${ }^{1}$ mas que foram rearranjados e adequados aos critérios avaliados nos equipamentos, de forma que o resultado da pesquisa, de um modo geral, demonstre o quanto os espaços visitados contemplam a acessibilidade para pessoas com deficiência (sensorial e motora) e mobilidade reduzida, visto que são espaços construídos para receber grande público na cidade. Vários são os aspectos e sutilezas de um espaço acessível às mais diversas deficiências, nesta pesquisa, optamos por elencar oito itens que se desdobram em vários aspectos e critérios que, de certa forma, abrangem boa parte do que se tem como oferta de um espaço de características acessíveis.

Os aspectos avaliados foram os seguintes.

1. Quanto às áreas de acesso do edifício:

- Existência de rampa ou equipamento eletromecânico no caso de desnível entre a circulação externa e a porta de entrada do edifício;

- Tratamento de desníveis superior a $5 \mathrm{~cm}$;

- Piso regular, firme, estável, não trepidante e antiderrapante;

- Faixa faixa livre contínua, com largura mínima de 1,2 m e altura mínima de 2,10 m, com inclinação transversal inferior à 3\%;

2. Quanto à comunicação e sinalização:

- Mapa tátil ou sinalização para circulação horizontal, vertical, sanitário e saídas de emergência;

- Balcão de informação localizado em rota acessível;

- Contraste de cores entre piso, parede e móveis;

3. Quanto às circulações horizontais:

- Corredores com larguras mínimas de 1,50 m;

- Pisos com superfícies regulares, firmes, não trepidantes;

- Chanfro para desníveis menores que $20 \mathrm{~mm}$ ou rampas para desníveis maiores que 20mm;

- Existência de linha-guia identificável ou piso tátil;

- Guarda-corpos com altura mínima de 1,05 m;

4. Quanto às circulações verticais:

- Existência de equipamentos eletromecânicos, elevador - vão livre da porta de $80 \mathrm{~cm}$;

- Escadas e patamares com largura mínima de 1,20 m, patamares com piso antiaderente e firme, degraus com altura entre $16 \mathrm{~cm}$ e $18 \mathrm{~cm}$ e profundidade entre $28 \mathrm{~cm}$ e $32 \mathrm{~cm}$, corrimãos com duas alturas de $92 \mathrm{~cm}$ e $70 \mathrm{~cm}$, guarda-corpos com altura mínima de 1,05 m, guias de balizamento;

- Rampas com largura mínima de 1,20 m, inclinação máxima de 8,33\%, guia de balizamento de $5 \%$ caso não haja paredes laterais, inclinação transversal máxima de $2 \%$ para rampas internas e $3 \%$ para rampas externas, corrimãos com as duas alturas de $92 \mathrm{~cm}$ e $70 \mathrm{~cm}$, guarda-corpos com altura mínima de 1,05 m;

- Sinalização tátil, sonora, visual;

5. Quanto às portas:

- Vãos com 0,80 m de largura;

- Maçanetas com altura entre $0,80 \mathrm{~m} \mathrm{e} 1,10 \mathrm{~m}$;

- Desníveis nas soleiras de no máximo $5 \mathrm{~mm}$;

- Faixa de sinalização visual emoldurando paredes envidraçadas;

${ }^{1}$ Ver procedimentos metodológicos em Relatório de Pesquisa de Santiago et al (2015). 
6. Quanto ao mobiliário:

- Balcões de atendimento localizados em rotas acessíveis, com altura livre de $73 \mathrm{~cm}$ e profundidade inferior de $30 \mathrm{~cm}$;

- Iluminação ambiente;

- Mobiliário para espera fora da faixa livre de circulação;

- Inclinação dos assentos entre $100^{\circ}$ e $110^{\circ}$;

7. Quanto aos sanitários:

- Portas com 0,80 m mínimo de vão livre. Área livre de de 0,6 m sem interferência da área de varredura da porta;

- Barras de apoio com altura do piso de 0,75 m e comprimento mínimo de 0,70 m;

- Os acessórios do sanitário como papeleiro, toalheiros, cabides estão instaladas em altura confortável entre $0,80 \mathrm{~m}$ e $1,20 \mathrm{~m}$;

- Contraste de cor entre piso e paredes;

8. Quanto ao estacionamento:

- Vagas reservadas para pessoas com deficiência, próximas ao acesso do edifício;

- Quando afastadas da faixa de pedestre, as vagas possuem um espaço adicional de circulação de largura mínima de 1,20 m;

Inicialmente, observamos o acesso do equipamento e suas características, como o tipo de piso; se apresentava regularidade e sem trepidações, além da inclinação transversal, pois desnivelamentos prejudicam o caminhar de pessoas com deficiência ou mobilidade reduzida, como também de crianças e idosos. O acesso até o equipamento precisa ter acessibilidade garantida, além da orientação pelos seus setores, que deve ser feita pelo uso de placas e guias, mapa tátil e comunicação visual e sonora, caracterizando os critérios de acesso e sinalização de grande importância para a acessibilidade.

Adentrando ao edifício, é importante verificar a existência de uma rota acessível iniciado na área externa deste ou de uma potencialmente acessível, em que as circulações horizontais e verticais estejam interligadas por meio de piso direcional e comunicação visual, além de possuírem larguras adequadas, piso nivelados e guarda-corpos com alturas estabelecidas pela NBR 9050/2015. Isso se aplica também às dimensões de portas e mobiliário, que devem otimizar as condições de uso com sua ergonomia.

Outro ponto analisado foi a condição de acessibilidade dos sanitários desses equipamentos, em que foram observados o contraste de cor entre piso e parede, altura de sanitários, papeleiras e saboneteiras e espaço para giro da cadeira de rodas de $360^{\circ}$. Quanto aos estacionamentos, foram analisadas a existência de vagas reservadas para pessoas com deficiência, idosos e faixa de circulação.

A quantidade de visitas para preenchimento das fichas se deu de acordo com as dimensões dos equipamentos, como por exemplo: o Centro Dragão do Mar de Arte e Cultura, localizado na Praça Almirante Saldanha, foram necessárias quatro visitas até que todos os parâmetros fossem analisados, ou ainda, o prédio da Justiça Federal, presente na Praça Murilo Borges, exigiu dois dias de análise. Deve-se ressaltar que junte-se ao tempo de pesquisa, a necessidade de conseguir autorização para análise com a diretoria de cada equipamento, pois se tratam de instituições prestadoras de serviços com funcionários e usuários em pleno uso. Em algumas ocasiões não houve a liberação para a pesquisa no interior do edifício, como no caso do Banco do Brasil, na Praça Waldemar Falcão, que foi justificada por questões de segurança interna, apenas os acessos e áreas comuns foram autorizados à vistoria.

Após a fase de verificação do checklist, cada parâmetro foi avaliado da seguinte forma: 


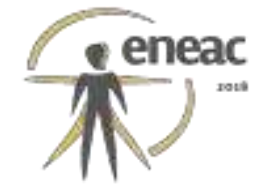

- Existe e Adequado (EA) - quando a característica supre as necessidades conforme as normas;

- Existe e Inadequado (EI) - quando há aspectos que não estão completamente de acordo com as normas e precisam ser melhorados;

- Não Existe (NE) - quando nenhuma característica do critério é seguida tal como a norma ou realmente nada existe;

- Parâmetro Não Avaliado (PNA) - quando não houve a possibilidade de avaliação do parâmetro, como foi o caso do Teatro São José, na Praça do Cristo Redentor, que não pode ser avaliado por estar em reforma no período da pesquisa.

\section{RESULTADOS}

Apresentamos os seguintes resultados da análise dos equipamentos vinculados às praças públicas do Centro, de acordo com critérios de acesso, sinalização, circulação horizontal, circulação vertical, portas, mobiliário, sanitário e estacionamento. Os resultados foram reunidos no Quadro 2, no qual foram quantificados e calculados percentuais referentes à situação de acessibilidade em cada equipamento, conforme a legenda explicitada anteriormente (EA; El; NE; PNA).

QUADRO 2 - Dados coletados nos equipamentos vinculados às praças públicas do Centro.

\begin{tabular}{|l|c|c|c|c|c|c|c|c|}
\hline \multicolumn{7}{|c|}{ DADOS COLETADOS NOS EQUIPAMENTOS DAS PRAÇAS PÚBLICAS DO CENTRO } \\
\begin{tabular}{|l|c|c|c|c|c|} 
Eqipamento Praça \\
e
\end{tabular} & Acesso & Sinalização & $\begin{array}{c}\text { Circ. } \\
\text { Horizontal }\end{array}$ & $\begin{array}{c}\text { Circ. } \\
\text { Vertical }\end{array}$ & Portas & Mobiliário & Sanitário & $\begin{array}{c}\text { Estaciona } \\
\text { mento }\end{array}$ \\
\hline $\begin{array}{l}\text { Centro Dragão do Mar de } \\
\text { Arte e Cultura - Praça } \\
\text { Almirante Saldanha }\end{array}$ & EI & EI & EA & EI & EA & EI & EI & EA \\
\hline $\begin{array}{l}\text { Teatro São José - Praça } \\
\text { Cristo Redentor }\end{array}$ & PNA & PNA & PNA & PNA & PNA & PNA & PNA & PNA \\
\hline $\begin{array}{l}\text { Igreja Do Carmo - Praça Do } \\
\text { Carmo }\end{array}$ & EI & NE & EI & PNA & EI & PNA & EI & PNA \\
\hline $\begin{array}{l}\text { Passeio Público - Praça } \\
\text { dos Mártires }\end{array}$ & EI & NE & EI & PNA. & EI & EI & EI & PNA \\
\hline $\begin{array}{l}\text { Escola Normal- } \\
\text { Praça Figueira de Melo }\end{array}$ & PNA & PNA & PNA & PNA & PNA & PNA & PNA & PNA \\
\hline $\begin{array}{l}\text { Igreja Nossa Senhora do } \\
\text { Rosário - Praça General } \\
\text { Tibúrcio }\end{array}$ & EI & NE & EI & EI & EI & EI & PNA & PNA \\
\hline $\begin{array}{l}\text { Banco do Brasil - Praça } \\
\text { Waldemar Falcão }\end{array}$ & EI & NE & PNA & PNA. & PNA & PNA. & PNA & PNA \\
\hline $\begin{array}{l}\text { Correios - Largo } \\
\text { do Mercado }\end{array}$ & EI & NE & EI & EI & EA & EI & EI & PNA \\
\hline $\begin{array}{l}\text { Largo da Assembléia - } \\
\text { Largo da Assembléia }\end{array}$ & PNA & PNA & PNA & PNA & PNA & PNA & PNA & PNA \\
\hline $\begin{array}{l}\text { Justiça Federal - } \\
\text { Praça Murilo Borges }\end{array}$ & EI & EI & EA & EI & EA & EI & EA & PNA \\
\hline
\end{tabular}




\begin{tabular}{|c|c|c|c|c|c|c|c|c|}
\hline $\begin{array}{l}\text { Parque da Criança - } \\
\text { Parque da Liberdade }\end{array}$ & EI & EI & EI & EI & EA & EI & PNA & PNA \\
\hline $\begin{array}{l}\text { Câmara dos Dirigentes } \\
\text { Lojistas (CDL) - Parque } \\
\text { Pajeú }\end{array}$ & EI & EI & EA & EA & EA & EI & EA & EI \\
\hline $\begin{array}{l}\text { Igreja Sagrado Coração de } \\
\text { Jesus - Praça José Júlio }\end{array}$ & EI & NE & El & PNA & EI & PNA & EI & PNA \\
\hline $\begin{array}{l}\text { Mercado São Sebastião - } \\
\text { Praça Paulo Pessoa }\end{array}$ & EI & NE & EA & EI & EA & EI & EI & EA \\
\hline $\begin{array}{l}\text { Mercado dos Pinhões - } \\
\text { Praça Visconde de Pelotas }\end{array}$ & EI & NE & EA & EI & EA & EI & $\mathrm{NE}$ & PNA \\
\hline $\begin{array}{l}\text { IPHAN - Praça José de } \\
\text { Alencar }\end{array}$ & EI & $\mathrm{NE}$ & EI & EI & EA & PNA & EI & PNA \\
\hline PORCENTAGENS & $\begin{array}{c}\text { EA } \\
0 \% \\
\text { EI } \\
\begin{array}{c}81,2 \\
\%\end{array} \\
\\
\text { NE } \\
0 \% \\
\\
\text { PNA } \\
\begin{array}{c}18,8 \\
\%\end{array}\end{array}$ & $\begin{array}{c}\text { EA } \\
0 \% \\
\\
\text { El. } \\
25 \% \\
\text { NE } \\
56,25 \% \\
\text { PNA } \\
18,75 \%\end{array}$ & $\begin{array}{c}\text { EA } \\
31,25 \% \\
\text { EI } \\
43,75 \% \\
\text { NE } \\
0 \% \\
\text { PNA } \\
25 \%\end{array}$ & $\begin{array}{c}\text { EA } \\
6,3 \% \\
\text { EI } \\
50 \% \\
\\
\text { NE } \\
0 \% \\
\\
\text { PNA } \\
43,7 \\
\%\end{array}$ & $\begin{array}{c}\text { EA } \\
.50 \% \\
\\
\text { El } \\
25 \% \\
\\
\text { NE } \\
0 \% \\
\\
\text { PNA } \\
25 \%\end{array}$ & $\begin{array}{c}\text { EA } \\
0 \% \\
\text { EI } \\
56,2 \% \\
\text { NE } \\
0 \% \\
\text { PNA } \\
43,8 \%\end{array}$ & $\begin{array}{c}\text { EA } \\
12,5 \% \\
\text { EI } \\
43,8 \% \\
\text { NE } \\
6,25 \% \\
\text { PNA } \\
37,45 \%\end{array}$ & $\begin{array}{c}\text { EA } \\
12,5 \% \\
\text { El. } \\
6,25 \% \\
\text { NE } \\
0 \% \\
\text { PNA } \\
81,25 \%\end{array}$ \\
\hline
\end{tabular}

Fonte: Equipe da Pesquisa, 2017.

Analisando os resultados constatamos que muitos dos acessos não possuem inclinações adequadas nos desníveis e rampas, pisos trepidantes e irregulares que não facilitam o percurso de uma pessoa com deficiência, além de piso direcional na mesma cor que o piso geral (Fotos 1 e 2), o que é agravado pela sinalização insuficiente, informação que pode ser validada pela inexistência de mapa tátil em todos os equipamentos visitados.

Foto 1: Parque da Criança. $\quad$ Foto 2: Mercado S. Sebastião.

Foto 3: Dragão do Mar.

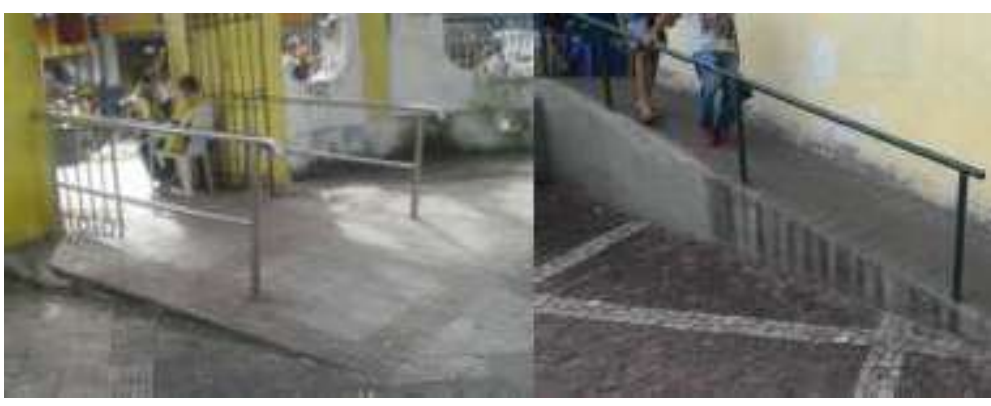

Fonte: Arquivo da Pesquisa.
Fonte: Arquivo da Pesquisa.

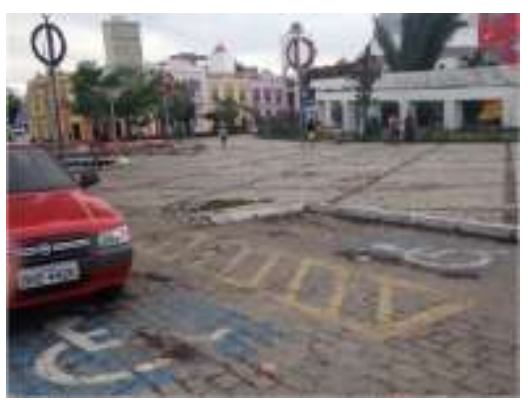

Fonte: Arquivo da Pesquisa.

Os estacionamentos (Foto 3), em sua maioria, não possuem vagas com aproximação diretamente aos prédios, portanto, poucas são as reservas de vagas para idosos ou pessoas com deficiência. Os usuários e transeuntes compartilham as vagas que existem nas praças com os usuários das edificações vizinhas ou, simplesmente não há onde 


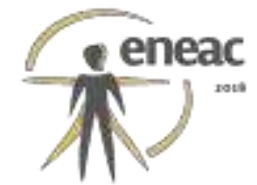

estacionar. Em outros estacionamentos, como é o caso do CDL, a entrada e saída de carros interrompe a calçada com desnível, tendo ainda os tachões redutores de velocidade correspondente a faixa livre da calçada, o que pode causar acidentes ao pedestre (Foto 4).

Nas vagas reservadas, a sinalização está posicionada de forma inadequada, pois se encontra exatamente onde deveria ter o rebaixamento de guia para fazer a rota acessível, de quem sai do carro na faixa amarela em cadeira de rodas para ter acesso à calçada e à porta de entrada (Foto 5). Somente uma faixa amarela está com rebaixamento correspondente, embora o piso seja em pedra portuguesa que muitas vezes não é de dimensionamento apropriado nem de bom assentamento (Foto 6).

Foto 4: Acesso estacionamento no CDL

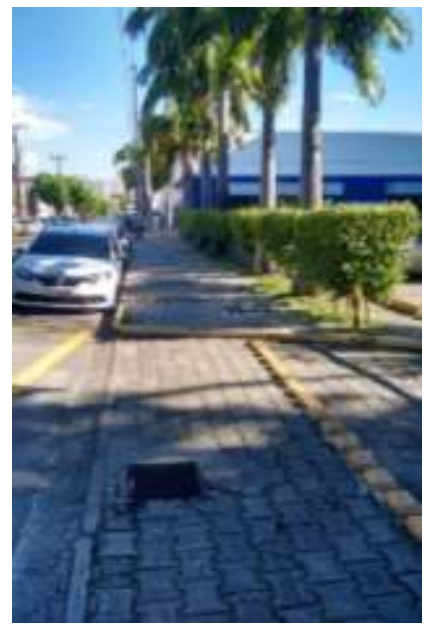

Fonte: Arquivo da Pesquisa.
Foto 5: Vagas reservadas no CDL

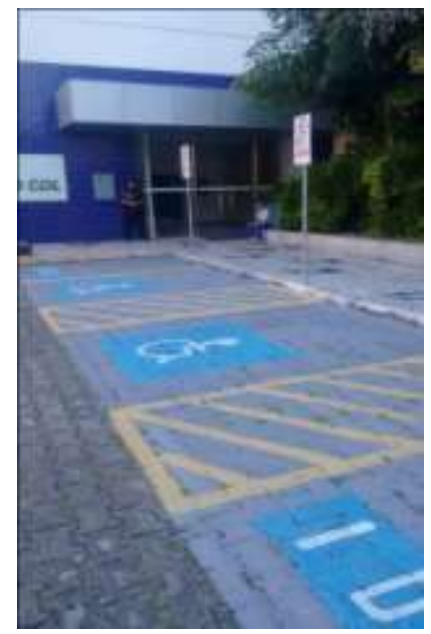

Fonte: Arquivo da Pesquisa.
Foto 6: Rebaixo de guia no CDL

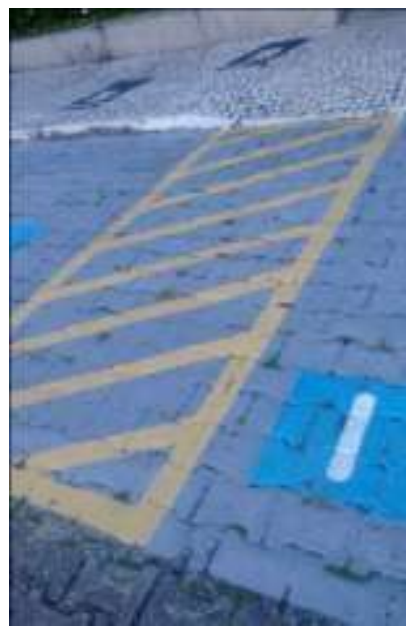

Fonte: Arquivo da Pesquisa.

Tanto as circulações horizontais (Ver Foto 7) e verticais apresentam aspectos que podem ser melhorados, como aspectos de piso tátil direcional e de alerta, além de alturas de corrimãos e guarda-corpos, nivelamento do piso e inclinações.

Foto 7: Mercado dos Pinhões.

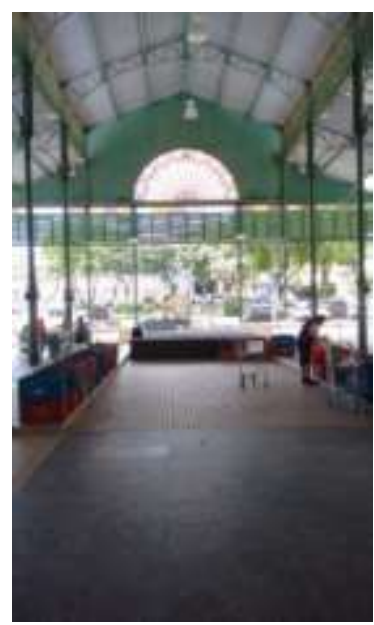

Fonte: Arquivo da Pesquisa
Foto 8: Câmara D. Lojistas

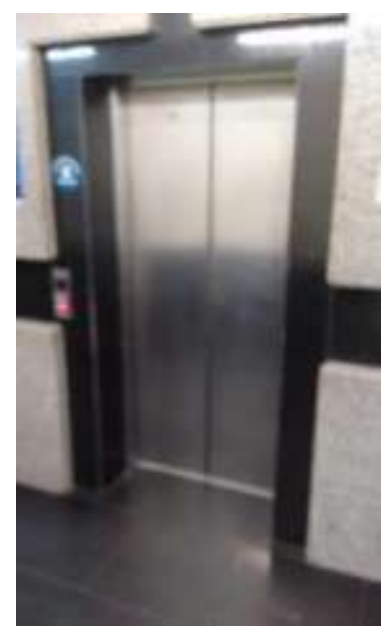

Fonte: Arquivo da Pesquisa
Foto 9: Justiça Federal

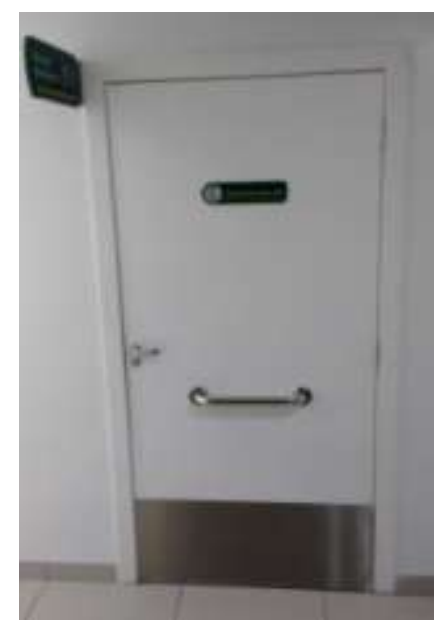

Fonte: Arquivo da Pesquisa 


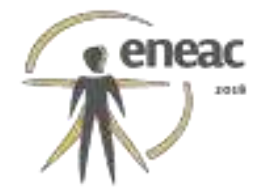

Alguns elementos foram incorporados nos ambientes que denotam a iniciativa no sentido de contemplar a acessibilidade, contudo, existem ainda muitas falhas, como a falta de sinalização - piso tátil - , em frente ao elevador (Foto 8) e a plaqueta de sinalização do ambiente, normalmente de altura não adequada a pessoas em cadeira de rodas e pessoas com deficiência visual.

As portas (Foto 9) são os itens que mais se aproximam das recomendações normativas, em relação ao tipo de maçaneta e largura de porta, enquanto que o mobiliário avaliado se mostrou pouco eficiente, como os balcões de recepção que não possuem altura compatível com as recomendações das normas dificultando a aproximação e comunicação da pessoa em cadeira de rodas ou de pouca estatura (Foto 10). Alguns balcões de atendimento se apresentaram de forma coerente pela altura e área de aproximação (Foto 11).

Quanto aos sanitários destas edificações, o principal problema encontrado foi a irregularidade nas alturas de barras de apoio, de pias, saboneteiras e papeleiras, contudo, é perceptível certa preocupação por parte das administrações dos equipamentos em adequar esse critério às exigências de seus usuários, embora a adaptação nem sempre seja exitosa, apresentando falhas quanto ao tipo de vaso sanitário, inexistência da barra de apoio na parede posterior e barra vertical, como também, posicionamento de altura inadequada da descarga (Foto 12).

Foto 10: Balcão de recepção Centro de Arte e Cultura Dragão do Mar

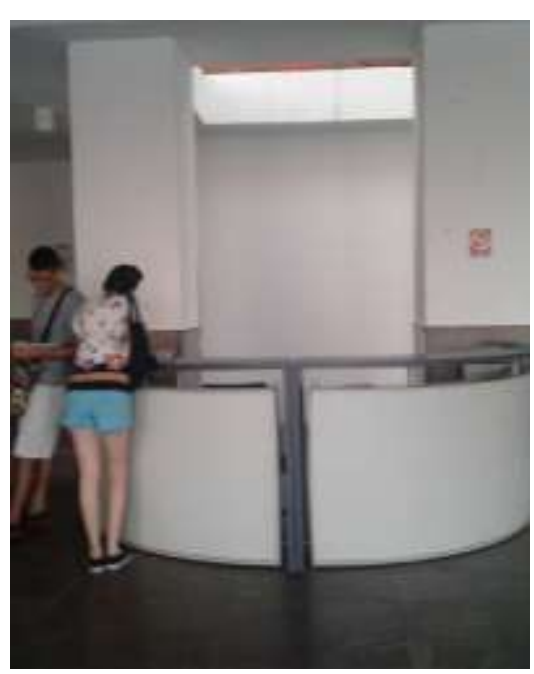

Fonte: Arquivo da Pesquisa.
Foto 11: Balcão de atendimento - Justiça Federal

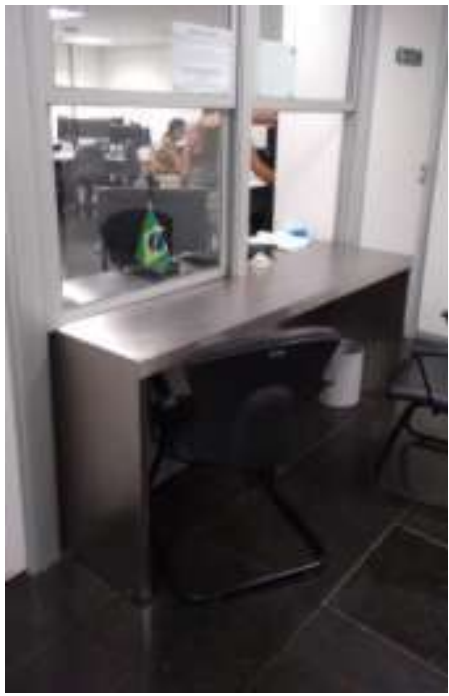

Fonte: Arquivo da Pesquisa.
Foto 12: WC - CDL

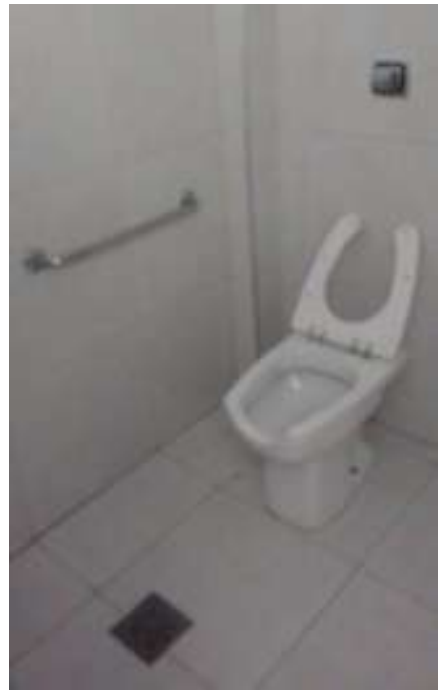

Fonte: Arquivo da Pesquisa.

É compreensível e necessário, no entanto, considerar o caráter histórico de alguns dos equipamentos avaliados, como a Igreja do Carmo na Praça de mesmo nome, Igreja do Rosário na Praça dos Leões (Foto 13 e 14), Igreja Sagrado Coração de Jesus na Praça José Júlio e Mercado dos Pinhões na Praça Visconde de Pelotas (Foto 15), que foram construídos em épocas em que a ideia da inclusão não existia ou pelo menos era pouco difundida, não havia a legislação relativa à acessibilidade e que, ainda, reformas agressivas podem vir a descaracterizar estas obras. A Igreja do Rosário é antiga, bem pequena e por isso suas circulações são comprometidas quanto à acessibilidade. 


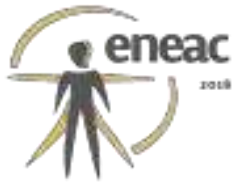

Foto 13: Igreja do Rosário

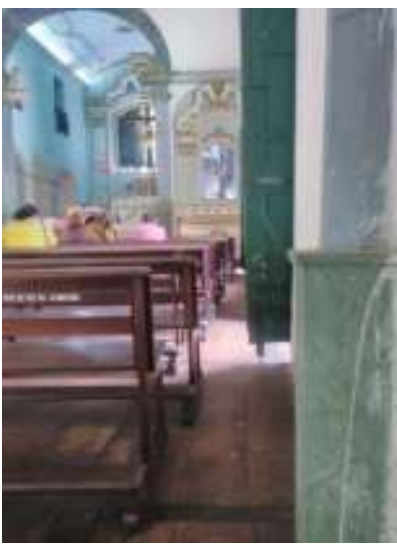

Fonte: Arquivo da Disciplina de Desenho Universal ${ }^{2}$.
Foto 14: Praça dos Leões

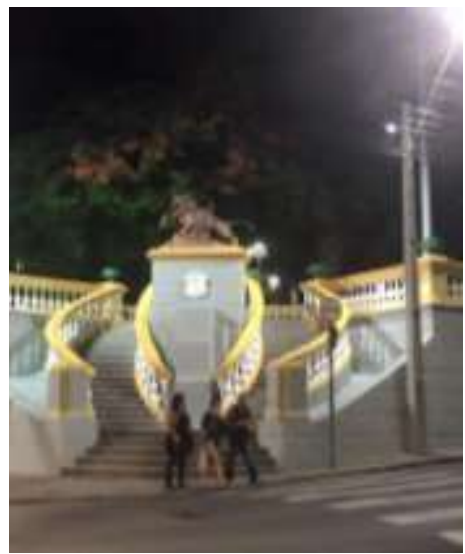

Fonte:Elodie Bomfim Hyppolito - In: Fortaleza Antiga, 28/01/2017
Foto 15: Mercado dos Pinhões

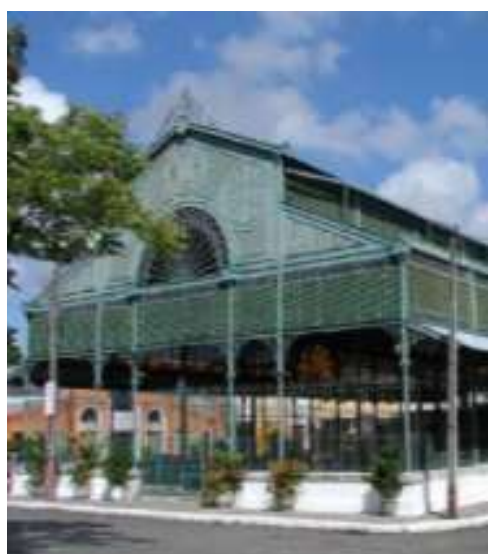

Fonte:Google Earth

De fato, é inteligível que os equipamentos avaliados oferecem serviços de grande abrangência à população, devido sua importância para a cidade de Fortaleza, como pólos de cultura, lazer, informações, entre outros, por outro lado, este fato, torna ainda mais importante a democratização de acesso desses espaços, que precisam receber adequadamente qualquer pessoa para desfrute desses ambientes.

\section{CONSIDERAÇÕES FINAIS}

Após análise dos resultados é possível afirmar que a situação da acessibilidade e do desenho universal nos equipamentos avaliados é precária em relação a grande parcela dos critérios estabelecidos: acessos, circulações horizontais e verticais, mobiliários e sanitários. Existente em sua maioria de forma adequada apenas as portas, enquanto que a sinalização visual e/ou sonora não existe na maior parte dos equipamentos. Quando são analisados os detalhes das construções é perceptível a não existência de elementos acessíveis ou inadequações com as recomendações da NBR 9050/2015, NBR 16.537/2016 e o Decreto 5.296, de 2 de dezembro de 2004, seja por se tratar de construções bem anteriores à legislação, seja pelo descuido nos projetos de adaptação ou na execução da obra de reforma.

Para uma receptividade mais ampla das pessoas com deficiência ou com mobilidade reduzida, idosos e crianças nos espaços de convívio público e coletivo é necessária a disseminação da cultura da inclusão, o que justifica a importância de pesquisas voltadas para este campo de estudo, principalmente em se tratando de um tema que deve ser de conhecimento geral da sociedade. A participação destas pessoas em discussões que envolvem as tomadas de decisões e em projetos é fundamental para garantia do diálogo, contribuindo para que cheguemos à realidade de cidades inclusivas.

\section{REFERÊNCIAS BIBLIOGRÁFICAS}

ASSOCIACÃO BRASILEIRA DE NORMAS TÉCNICAS . NBR 9050: Acessibilidade a edificações , mobiliário, espaços e equipamentos urbanos. Rio de Janeiro: ABNT, 2015.

\footnotetext{
${ }^{2}$ Relatório de Estudo Vistoria das Condições de Acessibilidade Igreja do Rosário (2017). Alunos: Emanuel Alves, Hadryel Oliveira, Hérika Felipe, Gislyane Felix.
} 


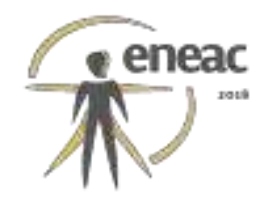

ASSOCIACÃO BRASILEIRA DE NORMAS TÉCNICAS . NBR 16537: Acessibilidade - Sinalização tátil no piso - Diretrizes para elaboração de projetos e instalação. Rio de Janeiro: ABNT, 2016.

BRASIL. Decreto No 5.296, de 2 de dezembro de 2004. Regulamenta as Leis nos 10.048, de 8 de novembro de 2000, que dá prioridade de atendimento às pessoas que especifica, e 10.098, de 19 de dezembro de 2000, que estabelece normas gerais e critérios básicos para a promoção da acessibilidade das pessoas portadoras de deficiência ou com mobilidade reduzida, e dá outras providências.

IBGE, Censo Demográfico, 2010: Disponível em http://www.ibge.censo2010.gov.br Acesso em: 01/12/2017.

ORNSTEIN, Sheila; ROMÉRO, Marcelo. Avaliação Pós-Ocupação do Ambiente Construído. São Paulo: Nobel, 1992.

RHEINGANTZ, Paulo Afonso... [et al.]. Observando a qualidade do lugar: procedimentos para a avaliação pós-ocupação -- Rio de Janeiro : Universidade Federal do Rio de Janeiro, Faculdade de Arquitetura e Urbanismo, Pós- Graduação em Arquitetura, 2009. 117 p. : il. color. ; 21 cm. - (Coleção PROARQ)

SANTIAGO, Zilsa Maria Pinto; SANTIAGO, Cibele Queiroz de; SOARES, Thais Silveira. Acessibilidade no Espaço Público: o caso das Praças de Fortaleza, p. 260-271. In: Anais do 15을 Ergodesign \& Usihc [=Blucher Design Proceedings, vol. 2, num. 1]. São Paulo: Blucher, 2015.

SANTIAGO, Zilsa Maria Pinto; SANTIAGO, Cibele Queiroz de; SOARES, Thais Silveira. Relatório Técnico de Pesquisa: Análise das condições de acessibilidade espacial de praças e equipamentos sociais sob o enfoque do desenho universal. Estudos de caso: Centro e bairros Aldeota; Fátima e Benfica em Fortaleza. PIBIC 2014/2015 - Edital 01/14. Pró-Reitoria de Pesquisa e Pós-Graduação. Universidade Federal do Ceará, 2015.

SANTIAGO, Zilsa Maria Pinto; ROCHA, Carlos Bruno Oliveira. Relatório Técnico de Pesquisa: ESPAÇO PÚBLICO E ESPAÇO EDIFICADO: uma análise de equipamentos sociais agregados às praças de Fortaleza sob o enfoque da acessibilidade universal. PIBIC 2016/2017 - Edital 02/16. Pró-Reitoria de Pesquisa e Pós-Graduação. Universidade Federal do Ceará, 2017.

SANTIAGO, Zilsa Maria Pinto. Acessibilidade física no ambiente construído: o caso das escolas municipais de ensino fundamental de Fortaleza - CE (1990 - 2003). Dissertação de Mestrado FAUUSP. São Paulo, 2005.

\section{AGRADECIMENTOS}

Nossos agradecimentos ao CNPq pelo auxílio financeiro de cotas de IC em forma de bolsa ao Programa Institucional de Bolsas de Iniciação Científica_PIBIC/UFC. 